\title{
Non-Verbal Intelligence in Primary School Students: A Cross-Cultural Study
}

\author{
Yulia Davydova ${ }^{1}$, Ilia Zakharov², Irina Lysenkova ${ }^{1}$, Tamara Malykh ${ }^{2}$ and Victoria Ismatullina, ${ }^{2, *}$ \\ ${ }^{1}$ Kyrgyz-Russian Slavic University, 720000 Bishkek, Kyrgyzstan \\ ${ }^{2}$ Psychological Institute of Russian Academy of Education, 125009 Moscow, Russia
}

\begin{abstract}
In this article we present the results of a cross-cultural study of non-verbal intelligence in primary school students. Significant differences with the effect size of $9 \%$ were found in non-verbal intelligence scores of 1057 students from Russia and Kyrgyzstan. The differences were also found for city and countryside residents (effect size of 10\%). These results might be explained both by the features of educational systems and socio-economic development level in Russia and Kyrgyzstan.
\end{abstract}

\section{Introduction}

Cognitive abilities play an important role both in the life of an individual and the whole society [1 - 4]. Therefore, individual differences in intelligence may be the basis for the academic as well as professional success. Naturally, cognitive abilities studies has been drawing researchers' attention for many years $[5,6]$.

One of the methods for studying the formation of individual differences in psychological traits is the crosscultural analysis. Cross-cultural studies consider the cultural context as a source of individual differences and seek to reveal universal and culture-specific patterns of individual differences [7].

Studying these abilities in different cultures, thus conducting a large-scale natural experiment, is a way to assess the influence of culture, spoken and written language, nurturing and educational system on their development (for example, [8]). Several papers showed that these factors contribute significantly to the individual differences in non-verbal intelligence [3, 9]. Crosscultural differences are explained often by differences in features like thinking, for example, in East Asian (holistic thinking) and western (analytical thinking) cultures [9], differences in the structure of the language, such as Chinese characters and the Russian alphabet (e.g., [10]), and the type of cultural communities (ratio of the scales 'collectivism - individualism' and 'independence interdependence'). In particular, a significant positive effect of education on individual differences in intelligence was found in the Norwegian natural experiment, when as a result of the reform of public education two additional years of study after the seventh grade were introduced [11]. According to this study, the effect of prolonged educational process in adolescence on intelligence is significant at the age of 19 years [11]. It was also found that students who miss one year of schooling in the future show slightly lower results on intelligence tests [9]. Poor performance on intelligence tests in a number of studies was also associated with long summer holidays, when there is no systematic educational impact [9].

The present study is aimed at studying cross-cultural differences in non-verbal intelligence in Russian and Kyrgyz primary schoolchildren. Inclusion of students from these countries is of particular importance.

Firstly, these states have different human development index. According to the United Nations Development Programme, Russia occupies $55^{\text {th }}$ place in the ranking of countries by the human development index and is included in the group of countries with high human development rate, whereas Kyrgyzstan occupies $125^{\text {th }}$ place, which corresponds to the average level of human development. Secondly, the education systems in Russia and Kyrgyzstan are similar. Third, the quality of teaching high school students differs in the two countries. It was shown that in the Programme for International Student Assessment 15-year-old Russian schoolchildren were slightly below average (38-43) and the results of Kyrgyz students were at the last $65^{\text {th }}$ position.

These macro-environmental similarities and differences allow specifying universalism and cultural specificity in non-verbal intelligence at primary school age.

\section{Methods}

In total, the sample included 1057 primary school students aged from 7 to 9: 629 Russian (53.9\% boys) and 428 Kyrgyz (45.3\% boys).

Corresponding author: victoria2686@gmail.com 
We used Raven's Progressive Matrices (SPM) to assess their non-verbal intelligence [12]. It should be noted that, on the one hand, the test 'Raven Progressive Matrices' is positioned as independent of cultural context among intelligence tests. The literature emphasizes the central position of this test: it is assumed that the test 'Raven Progressive Matrices' is the most 'pure' of the existing measures of intelligence as a latent characteristic [13]. These characteristics are achieved through the use of abstract stimuli that are able to neutralize the influence of the cultural context in the strict compliance with the test instructions and differential item functioning analysis (DIF-analysis).

\section{Results and discussion}

First, we analyzed sex and age differences in non-verbal intelligence. Table 1 presents the descriptive statistics for non-verbal intelligence in Russian and Kyrgyz boys and girls. One-way ANOVA did not show any significant sex differences neither for the Russian $(p=0.908)$ nor for the Kyrgyz sample $(p=0.076)$.

Table 1. Means and standard deviations for non-verbal intelligence in primary school students in Russia and Kyrgyzstan (boys and girls).

\begin{tabular}{|l|c|c|}
\hline & Boys & Girls \\
\hline Russia & $38.72(9.4)$ & $38.63(8.5)$ \\
\hline Kyrgyzstan & $30.77(9.67)$ & $32.38(9.01)$ \\
\hline
\end{tabular}

In order to assess the age differences in both samples, three groups were compared in the analysis: 7-, 8- and 9year-old Russian and Kyrgyz students (table 2).

Table 2. Means and standard deviations for non-verbal intelligence in 7-, 8- and 9-year-old primary school students in Russia and Kyrgyzstan.

\begin{tabular}{|l|l|l|l|}
\hline & \multicolumn{1}{|c|}{7 years } & \multicolumn{1}{c|}{8 years } & 9 years \\
\hline Russia & $23.67(3.2)$ & $35.8(9.46)$ & $40.2(8.34)$ \\
\hline Kyrgyzstan & $29(11.5)$ & $29.87(9.19)$ & $32.71(9.28)$ \\
\hline
\end{tabular}

The results suggest that there is a tendency for non-verbal intelligence to increase with age. The extent of this growth was different for each country: from 23.67 to 40.2 in Russia and from 29 to 32.71 in Kyrgyzstan. After the Bonferroni correction, the statistically significant differences were shown for all age groups in the Russian sample $(p=0.001)$ and for the 8- and 9-year-olds in the Kyrgyz sample $(p=0.01)$. The age factor explains about $6.6 \%$ and $2.4 \%$ dispersion of the non-verbal intelligence in Russian and Kyrgyz samples, respectively.

These results may be related to the quality and effectiveness of the educational system in these countries. The pre-school and primary school systems are similar in Russia and Kyrgyzstan as both of them have roots in the USSR practice: children start attending kindergarden at the age of 3 , followed by pre-school classes at 6 to 7 years old, then entering primary school at about 7 years of age. During the Grades 1-4, that constitute primary education in both countries, the general disciplines, such as mathematics, Russian, reading and natural sciences are all taught by one teacher.

Despite the observed similarity, the Kyrgyz educational system is less centralized and less effective. For example, even though there are general requirements for the primary program in all Kyrgyz schools, they may differ a lot due to the choice of specific textbooks. Moreover, the educational standards vary across regions, as well as the age of school entrance ranges from 6 to 8 years. Due to the Federal state educational standards in Russia, this particular system is much more centralized. As for the pre-school education quality, it is shown that more than $90 \%$ of the children in Russia have access to the kindergarden - whereas the rate is only 10 to $16 \%$ in Kyrgyzstan. The quality of school education itself is also a subject for differences: the Programme for International Student Assessment (PISA) places Russian students at the 38 to 41 place in the world rankings, whereas Kyrgyz students take the last $\left(65^{\text {th }}\right)$ place. The other meaningful indicator is the teachers' education level: $68.4 \%$ of all the primary school teachers pass the required pedagogical training. In Russia it is only after you have the professional training or the specialized high education in pedagogy that you are allowed to teach at any level.

We suppose that the differences in the effectiveness and quality of primary education in Russia and Kyrgyzstan mentioned above may account for the differences in non-verbal intelligence in these two samples.

The analysis of the role of social and cultural characteristics (such as the type of the living area or country) in the individual differences in non-verbal intelligence of primary school children showed that on average the Russian students scored higher than the Kyrgyz. Russian children living in the city showed the highest mean score, while the Kyrgyzstan schoolchildren from the rural area showed the lowest mean score.

Two-way ANOVA (table 3) with the factors of country and living area showed significant effect on nonverbal intelligence. The interaction of factors was also significant.

Table 3. Results of 2-way ANOVA.

\begin{tabular}{|c|c|c|c|c|}
\hline Factor & $\begin{array}{c}\text { Sum of } \\
\text { squares } \\
(\mathrm{SS})\end{array}$ & $\mathrm{F}$ & $\begin{array}{c}\mathrm{p}- \\
\text { value }\end{array}$ & $\eta^{2}$ \\
\hline «Country» & 7658,42 & 107,13 & 0,000 & 0,09 \\
\hline «Living area» & 8672,24 & 121,31 & 0,000 & 0,10 \\
\hline Interaction & 1089,83 & 15,24 & 0,000 & 0,01 \\
\hline
\end{tabular}

According to table 3, the effect size of the country factor was $9 \%$. The best score was showed by Russian schoolchildren $($ mean $=36.81)$, with the difference $=$ 0.40 . The living area factor accounted for $10 \%$ of the variance. The city schoolchildren's mean was 37.01 , the difference with the rural schoolchildren was 0.19 . The interaction effect was significant though the effect size was small $(1 \%)$. Non-verbal intelligence was higher in 
Russian children living in the city than for those in Kyrgyzstan and both Russian and Kyrgyz children living in rural areas. There were no significant diffrences between Russian and Kyrgyz children living in rural areas.

\section{Conclusions}

Overall, the results of our study show that social-cultural characteristics such as country or living area type affects individual differences in non-verbal intelligence of primary school children. The differences we found may be related to the educational system features as well as the socio-economic status of the countries. According to the UN Human Development Report, Russia and Kyrgyzstan have different Human Development Index. Russia is in the high index group ( $50^{\text {th }}$ rank), while Kyrgyzstan is in the medium group $\left(120^{\text {th }}\right.$ rank). Future research may address the informative analysis of the educational factors that lead to the cross-cultural differences in cognitive functioning.

The fact of the extent of cross-cultural differences increasing with the complexity of the test tasks is an additional argument about the educational effects on intellectual performance. As for the mechanisms of the relationship 'education - intelligence', it should be noted that the effect of education 'applies' not only to the increase in knowledge, but it also stimulates development of mental operations. Thus, a number of studies have documented the effect of education on both crystallized and fluid intelligence [14]. Possibilities of enhancing non-verbal intelligence with a variety of educational activities are described in a number of formative experiments (e.g., [15]). For example, in one of these studies it was shown that working memory training using verbal and visual-spatial stimuli improves the scores for 'Raven Progressive Matrices' [15]. It is assumed that the relationship of macro-environmental conditions and nonverbal intelligence might be mediated by training sessions aimed at cognitive processes that underlie successful performance on intelligence tests (e.g., speed of information processing, spatial memory).

\section{References}

1. K.V. Petrides,

T. Chamorro-Premuzic, N. Frederickson, A. Furnham, British Journal of Educational Psychology, 75, 2 (2005)
2. W. Johnson, M. McGue, W.G. Iacono, Developmental Psychology, 42, 3 (2006)

3. R.J. Sternberg, Wisdom, intelligence and creativity synthesized (Cambridge, 2006)

4. P. Hagmann-von Arx, J.T. Gygi, R. Weidmann, A. Grob, Frontiers in Psychology, 7 (2016)

5. U. Neisser, G. Boodoo, T.J.J. Bouchard, A.W. Boykin, N. Brody, S.J. Ceci, D.F. Halpern, J.C. Loehlin, R. Perloff, R.J. Sternberg, S. Urbina, American Psychology, 51, 2 (1996)

6. R.B. Cattell, Abilities: their structure, growth, and action (Houghton Mifflin, 1979)

7. D. Matsumoto, F.J.R. van de Vijver. Cross-cultural research methods in psychology (Cambridge University Press, 2011)

8. A. Demetriou, Z.X. Kui, G. Spanoudis, C. Christou, L. Kyriakedes, M. Platsidou, Intelligence, 33, 2, (2005)

9. R. Nisbett, J. Aronson, C. Blair, W. Dickens, J. Flynn, D. Halpern and E. Turkheimer . Intelligence: New findings and theoretical developments, American Psychologist, 67, 130-159 (2012)

10. M. Rodic, X. Zhou, T. Tikhomirova, W. Wei, Malykh S., Ismatulina V., Sabirova E., Davidova Y., M. Tosto, J-P. Lemelin and Y. Kovas, Developmental Science, 18, 165-174 (2015)

11. C.N. Brinch and T.A. Galloway (2011). Schooling in adolescence raises IQ. Oslo, Norway: Research Department of Statistics Norway.

12. J. Raven, Occupational user's guide: Raven's advanced progressive matrices \& mill hill vocabulary scale (Oxford Psychologists Press Ltd., 1994)

13. P.A. Carpenter, M.A. Just, P. Shell, Psychological review, 97, 404-431 (1990)

14. H. Rindermann, C. Flores-Mendoza and M. MansurAlves, Learning and Individual Differences, 20, 544548 (2010)

15. S.M. Jaeggi, B. Studer-Luethi, M. Buschkuehl, Y.F. Su, J. Jonides and W.J. Perrig, Intelligence, 38, 625-635 (2010) 